\title{
Composite Scaffolds Based on Silver Nanoparticles for Biomedical Applications
}

\author{
Jenel Marian Patrascu, ${ }^{1}$ Ioan Avram Nedelcu, ${ }^{2}$ Maria Sonmez, ${ }^{3}$ Denisa Ficai, ${ }^{2}$ \\ Anton Ficai, ${ }^{2}$ Bogdan Stefan Vasile, ${ }^{2}$ Camelia Ungureanu, ${ }^{2}$ Madalina Georgiana Albu, ${ }^{3}$ \\ Bogdan Andor, ${ }^{1}$ Ecaterina Andronescu, ${ }^{2}$ and Laura Cristina Rusu ${ }^{4}$ \\ ${ }^{1}$ Department of Orthopaedics, Traumatology, Urology and Imaging, Faculty of Medicine, "Victor Babeş" University of Medicine and \\ Pharmacy Timişoara, P-ţa Eftimie Murgu, No. 2, 300041 Timişoara, Romania \\ ${ }^{2}$ Faculty of Applied Chemistry and Material Science, Politehnica University of Bucharest, 1-7 Polizu Street, 011061 Bucharest, Romania \\ ${ }^{3}$ Collagen Department, Leather and Footwear Research Institute, 93 Ion Minulescu, 031215 Bucharest, Romania \\ ${ }^{4}$ Department of Technology of Materials and Devices in Dental Medicine, "Victor Babeş" University of Medicine and \\ Pharmacy Timişoara, P-ța Eftimie Murgu, No. 2, 300041 Timişoara, Romania
}

Correspondence should be addressed to Madalina Georgiana Albu; albu_mada@yahoo.com

Received 12 January 2015; Revised 19 February 2015; Accepted 25 February 2015

Academic Editor: Bin Li

Copyright (C) 2015 Jenel Marian Patrascu et al. This is an open access article distributed under the Creative Commons Attribution License, which permits unrestricted use, distribution, and reproduction in any medium, provided the original work is properly cited.

\begin{abstract}
This paper presents the synthesis, characterisation, and in vitro testing of homogenous and heterogeneous materials containing silver nanoparticles (nanoAg). Three types of antiseptic materials based on collagen (COLL), hydroxyapatite (HA), and collagen/hydroxyapatite (COLL/HA) composite materials were obtained. The synthesis of silver nanoparticles was realized by chemical reaction as well as plasma sputtering deposition. The use of chemical reduction allows the synthesis of homogenous materials while the plasma sputtering deposition can be easily used for the synthesis of homogeneous and heterogeneous support. Based on the in vitro assays clear antiseptic activity against Escherichia coli was relieved even at low content of nanoAg (10 ppm).
\end{abstract}

\section{Introduction}

Silver nanoparticles are of increasing interest for scientists due to their very good biological properties and limited side effects. Used since $1000 \mathrm{BC}$, silver proved its biocidal activity for a wide number of bacteria and recently it was also known to be active in the treatment of cancer [1]. As a consequence of silver multifunctionality (antiseptic [2], antitumoral [3, 4], and IR-sensitizing agent [5]) the number of published papers dealing with silver nanoparticles increases exponentially yearly, at present over 10000 papers [6] being indexed on SCOPUS database. The distribution of the published papers, per year, can be visualized in Figure 1 .

Silver nanoparticles are widely used for their biological activity as colloidal suspension [7-10] or in association with other materials [11-14]. Silver nanoparticles were associated with different components such as manganite [15], carbon nanotubes [16], hydroxyapatite [17, 18], and chitosan [19]. Mostly, silver nanoparticles play antibacterial [17] and antitumoral [3] role.

Collagen is widely used for many biomedical applications [20-22]. Adding of calcium phosphates to collagen resulted in composite materials which proved to be remarkable bone grafts [23-31]. A common shortcoming of these grafts is related to the high incidence of infection [32]. Most surgical interventions involve antibiotic administration [33] which could be avoided by using silver nanoparticles [10, 34, 35].

In the case of bone cancer, many times surgical resection is necessary. In order to treat bone cancer the multifunctional COLL/HA- $\mathrm{Fe}_{3} \mathrm{O}_{4}$ composite materials were proposed. The composite support assures a faster healing of the bone defect while magnetite can assure the necessary hyperthermia to 


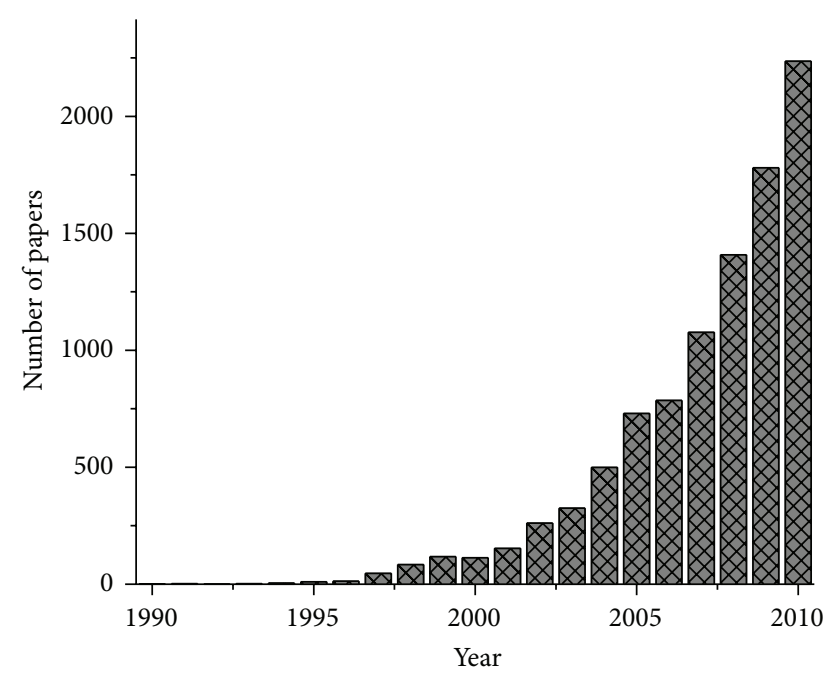

FIGURE 1: The evolution of the number of papers dealing with "silver nanoparticles."

induce tumoral cells death. It is also important to mention that magnetite can be activated, any time, by applying a proper, external electromagnetic field [36].

The current paper presents the synthesis and characterisation of new antiseptic materials based on silver nanoparticles embedded in collagen, hydroxyapatite, or collagen/ hydroxyapatite composite material. Silver nanoparticles were synthesised by two different methods: chemical reduction and plasma sputtering. The obtained materials are intended to be used as bone grafts.

\section{Materials and Methods}

Type I fibrillar collagen (C) gel having about $300000 \mathrm{Da}$, concentration of $1.6 \%(\mathrm{w} / \mathrm{w})$, and $\mathrm{pH} 7.4$ was extracted from calf hide as previously described [20,25].

Antiseptic collagen sponge was obtained by chemical reduction of $\mathrm{Ag}^{+}$in the presence of glucose and by plasma sputtering of Ag nanoparticles onto the collagen sponge. In both cases collagen sponge was obtained by cross-linking of the collagen gel with glutaraldehyde. For cross-linking 0.5\% glutaraldehyde, reported to dry collagen, was used.

The reduction of $\mathrm{Ag}^{+}$occurs in the presence of glucose which undergoes an oxidation process as presented in the following reaction:

$$
\mathrm{Ag}^{+}+\mathrm{C}_{6} \mathrm{H}_{12} \mathrm{O}_{6} \text { (glucose) } \longrightarrow \mathrm{Ag}^{0}+\mathrm{C}_{6} \mathrm{H}_{12} \mathrm{O}_{7}
$$

Antiseptic HA powder was also obtained by the same two methods starting from HA powder obtained by coprecipitation from $\mathrm{Ca}(\mathrm{OH})_{2}$ and $\mathrm{NaH}_{2} \mathrm{PO}_{4}$ [23].

The antiseptic composite materials were obtained by a similar way as antiseptic collagen sponge but starting from mineralized collagen gel and COLL/HA composite sponges, respectively.

The COLL/HA composite material was synthesised as we described in our previously published papers [25,37]. Briefly, the collagen gel (when plasma sputtering method is used) or silver containing collagen gel (when chemical method is used) was neutralized with $\mathrm{Ca}(\mathrm{OH})_{2} 24 \mathrm{~h}$ and then the proper amount of $\mathrm{NaH}_{2} \mathrm{PO}_{4}$ was added and let for other $24 \mathrm{~h}$ to interact. During these steps which lead to the HA nucleation on the collagen, the $\mathrm{pH}$ was set at 9. The final steps consist in cross-linking followed by freeze-drying.

Plasma sputtering of silver nanoparticles was realised using a BAL-TEC SCD005 Sputter Coater with nitrogen plasma and the deposition current was $59 \mathrm{~mA}$ while the deposition time was set at $60 \mathrm{~s}$.

The obtained materials were investigated by X-ray diffraction, IR spectroscopy, scanning electron microscopy, transmission electron microscopy, and antimicrobial activity against Escherichia coli.

$\mathrm{X}$-ray diffraction analysis was performed using a Shimadzu XRD 6000 diffractometer at room temperature. In all the cases, $\mathrm{Cu} \mathrm{K}{ }_{\alpha}$ radiation from a $\mathrm{CuX}$-ray tube was used. The samples were scanned in the Bragg angle, $2 \theta$ range of $10-70$.

For IR spectroscopy (Shimadzu 8400 FTIR Spectrometer) measurements, the spectra were recorded in the wavenumber range of $400-4000 \mathrm{~cm}^{-1}$, with a resolution of $2 \mathrm{~cm}^{-1}$.

SEM analyses were performed on a HITACHI S2600N electron microscope on samples covered with silver layer.

The transmission electron images were obtained on finely powdered samples using a Tecnai $\mathrm{G}^{2}$ F30 S-TWIN high resolution transmission electron microscope (HRTEM) equipped with STEM-HAADF detector, EDX, and EELS. The microscope was operated in transmission mode at $300 \mathrm{kV}$ while TEM point resolution was $2 \AA$ and line resolution was $1 \AA$.

The antibacterial activity was evaluated in triplicate against Escherichia coli. Escherichia coli (K 12-MG1655) were cultured in a tube containing Luria-Bertani (LB) medium [38] at $37^{\circ} \mathrm{C}$ (LB medium composition: peptone, $10 \mathrm{~g} / \mathrm{L}$; yeast extract $5 \mathrm{~g} / \mathrm{L}, \mathrm{NaCl} 5 \mathrm{~g} / \mathrm{L})$. Sterile samples were incubated for 18 hours in test tubes containing $5 \mathrm{~mL}$ culture of Escherichia coli. Culture was obtained from a volume of $100 \mathrm{~mL}$ sterile culture medium. The sterile medium was inoculated with $1 \mathrm{~mL}$ of Escherichia coli (1\%). Once obtained $5 \mathrm{~mL}$ of culture was placed over the samples. Optical density was determined after 18 hours of incubation. Incubation was performed in the incubator Laboshake Gerhardt. The bacterial growth was determined by measuring optical density for the four samples and control (Escherichia coli culture without sample) at $600 \mathrm{~nm}$ using UV-VIS spectrophotometer (Jenway Spectrophotometer).

The antibacterial activities were determined by calculating the inhibition of growth using [39]

$$
I \%=\frac{\left[\left(B_{18}-B_{0}\right)-\left(C_{18}-C_{0}\right)\right]}{\left(B_{18}-B_{0}\right)} \cdot 100,
$$

where $I$ is the inhibition of growth, $\%, B_{18}$ is the blankcompensated optical density at $600 \mathrm{~nm}\left(\mathrm{OD}_{600}=3.36\right.$ of the positive control of the organism at $18 \mathrm{~h}$ ), $B_{0}$ is the blankcompensated $\mathrm{OD}_{600}$ of the positive control of the organism at $0 \mathrm{~h}\left(\mathrm{OD}_{600}=0.049\right), C_{18}$ is the negative control-compensated $\mathrm{OD}_{600}$ of the organism in the presence of test sample at $18 \mathrm{~h}$, and $C_{0}$ is the negative control-compensated $\mathrm{OD}_{600}$ of the organism in the presence of test sample at $0 \mathrm{~h}$. 


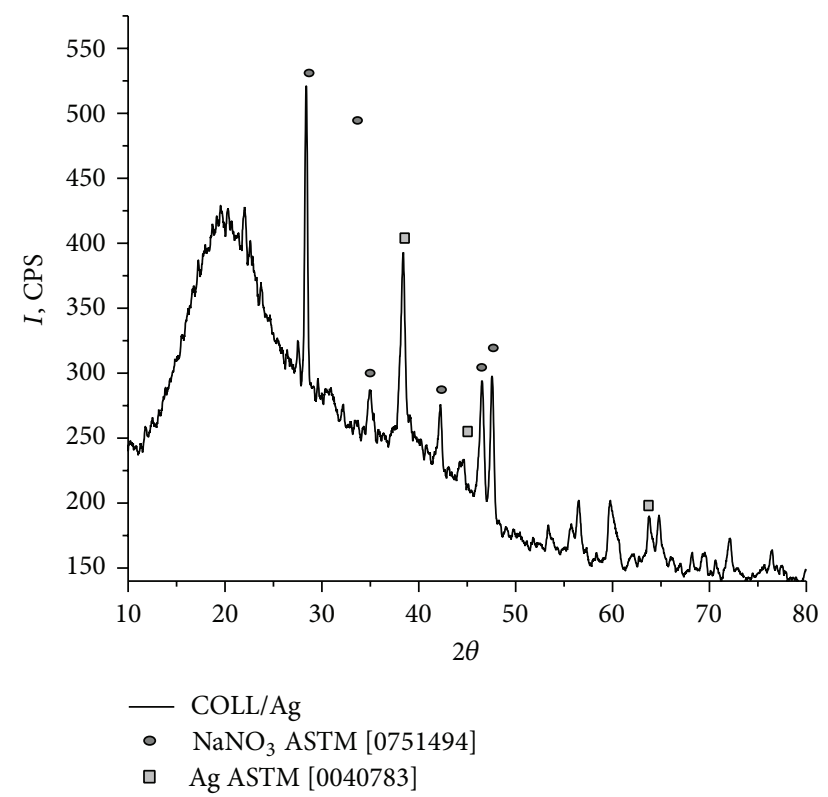

FIGURE 2: XRD pattern of COLL/Ag antiseptic composite materials.

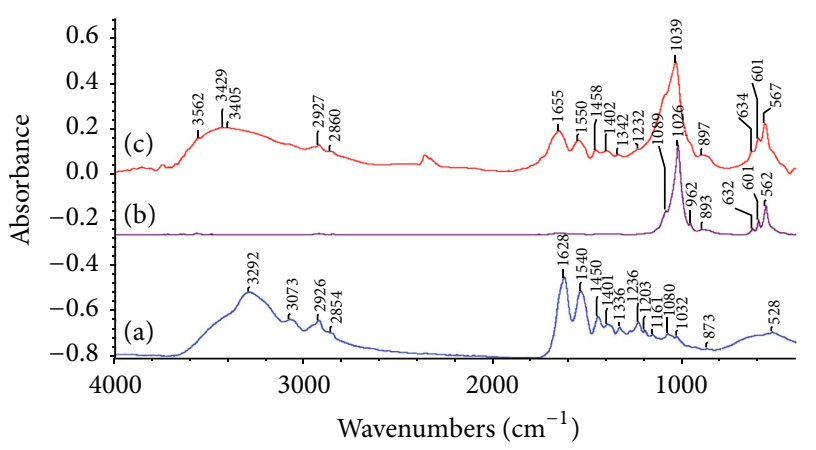

FIgURE 3: FTIR spectra of (a) COLL/Ag, (b) HA-Ag, and (c) COLL/HA-Ag antiseptic materials.

\section{Results and Discussion}

The antiseptic materials were characterized by appropriate methods.

3.1. X-Ray Diffraction. X-ray diffraction pattern was used to prove the formation of the AgNPs regardless of the synthesis method as we presented in Figure 2. Silver was identified based on the ASTM file number 0040783. Sodium nitrate was identified as a secondary crystalline phase, its presence being explained based on the collagen extraction technology.

3.2. Infrared Spectroscopy. The three FTIR spectra reveal the absorption bands of the components except the AgNPs which appear far below the lower limit of wavelength of the spectrophotometer as Figure 3 showed.

The main absorption band of HA appears as follows, a triple degenerate band associated with the O-P-O band at 560 , 600 , and $630 \mathrm{~cm}^{-1}$; a triple degenerate band at 1030, 1090, and $1110 \mathrm{~cm}^{-1}$; and a band associated with a symmetric stretch of P-O band at $960 \mathrm{~cm}^{-1}$, while the main absorption bands of collagen appear at 1628 (amide I), 1540 (amide II), 1236 (amide III), $2854\left(\mathrm{CH}_{2}\right.$ asymmetric stretching), $2926\left(\mathrm{CH}_{2}\right.$ symmetric stretching), and 2957 ( $\mathrm{CH}_{3}$ symmetric stretching). The wide band from 3000 to $3600 \mathrm{~cm}^{-1}$ corresponds to the associated hydroxyl groups from collagen, hydroxyapatite, and water.

3.3. Scanning Electron Microscopy. The silver particles cannot be identified by SEM images because of their low content and nanosize into the collagen composites (Figure 4). At 2000 and 3,500x magnification, the COLL/HA-Ag sample presents agglomerations which can be easily assigned to the inorganic, hydroxyapatite phase [24]. This observation is also supported by the comparison with the COLL/Ag sample (Figures 4( $\left.\mathrm{a}^{\prime}\right)$ $\left.4\left(c^{\prime}\right)\right)$ where no agglomerations can be identified. Silver visualization will be possible at higher magnification using TEM or HRTEM. That is why only in the case of COLL/HAAg composite material agglomerates can be visualised on the collagenic matrices, these agglomerates being clearly identified on the collagenic matrix at a magnification of $2000 \mathrm{x}$ while in the case of COLL/Ag material no agglomerations can be identified at this magnification.

Scanning electron microscopy was also used for the characterization of HA-Ag nanopowder (Figure 5). Based on the micrographs, it can be seen that nanometric particles were obtained. The size and shape are difficult to determine based on the SEM images and consequently TEM will be further used to evaluate the size and to determine the shape of these nanoparticles.

3.4. Transmission Electron Microscopy. TEM analysis was performed on pure silver nanoparticles obtained by plasma sputtering (Figure 6), COLL/Ag sample obtained by plasma sputtering (Figure 7), and HA-Ag nanopowder obtained by $\mathrm{HA}$ precipitation and chemical reduction of $\mathrm{Ag}^{+}$(Figure 8). In the case of pure silver nanoparticles obtained by plasma sputtering nanoAg agglomerates can be identified. From the point of view of particle size distribution very small particles with 1-2 $\mathrm{nm}$ as well as oversized particles with about $10-20 \mathrm{~nm}$ diameter can be visualized. The characteristic silver bands can be identified in SAED as well as silver oxide which means that during the deposition silver is partially oxidized to silver oxide.

In the case of COLL/Ag antiseptic sample, due to the collagen harsh matrix the silver is more uniformly deposited, the particles having generally $2-4 \mathrm{~nm}$ diameter.

Analyzing Figure 7, it can be seen that practically the particles are independent which means that collagen matrix acts as a dispersing agent and does not allow the silver nanoparticles to form agglomerates.

In the case of HA-Ag sample both $\mathrm{HA}$ and $\mathrm{Ag}$ can be identified based on their different contrast or based on their interplanar distances. At low magnification a severe agglomeration of the silver nanoparticles (darker nanoparticles) is noticed while, at high resolution characteristic planes of HA and Ag demonstrate their presence. Comparing with the COLL/Ag sample, the HA-Ag is less homogeneous because, 


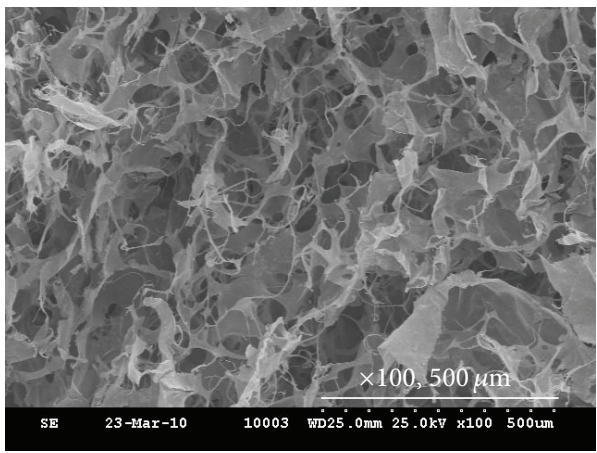

(a)

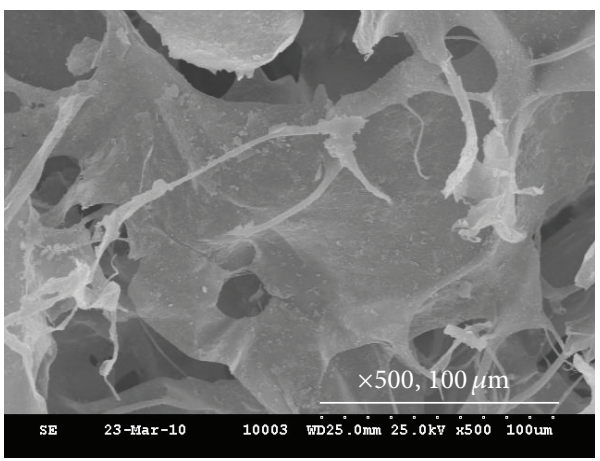

(b)

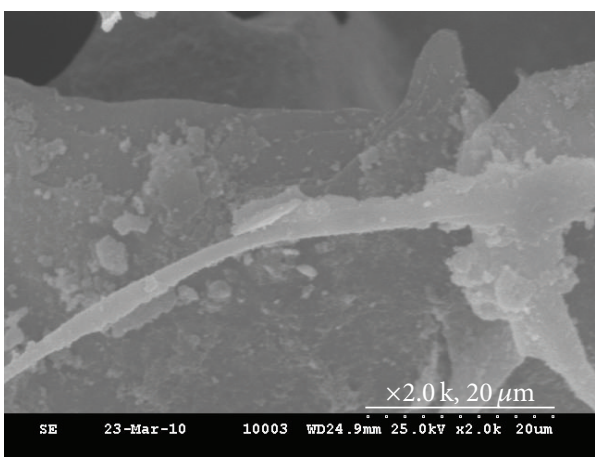

(c)

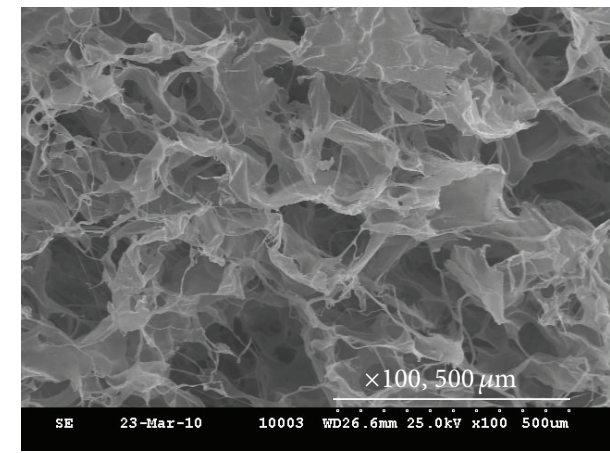

$\left(a^{\prime}\right)$

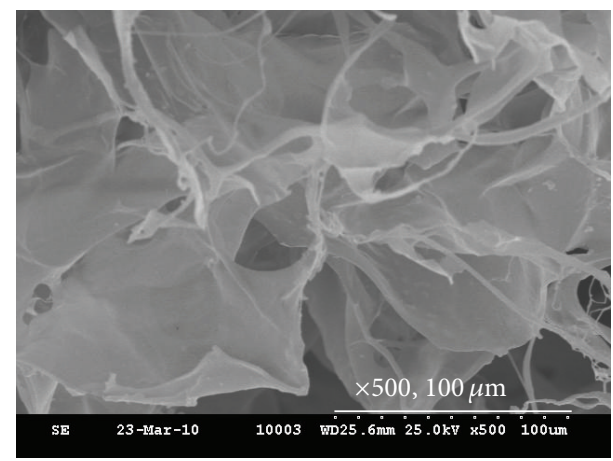

$\left(\mathrm{b}^{\prime}\right)$

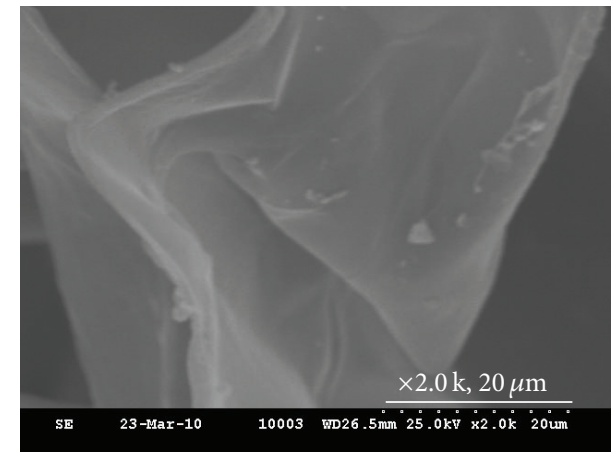

$\left(c^{\prime}\right)$

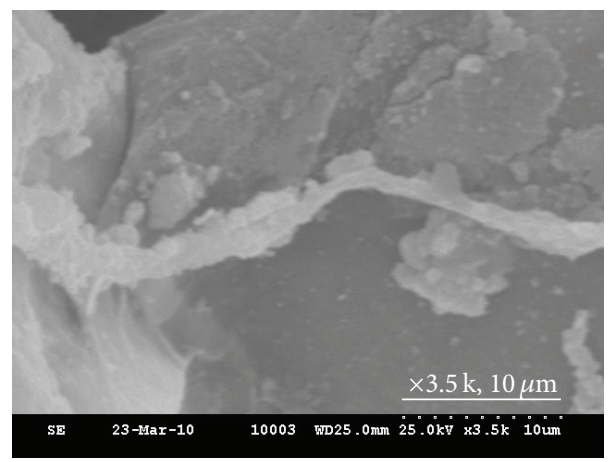

(d)

FIgURE 4: SEM images of (a)-(d) COLL/HA-Ag nanocomposite and $\left(a^{\prime}\right)-\left(c^{\prime}\right)$ COLL/Ag. 

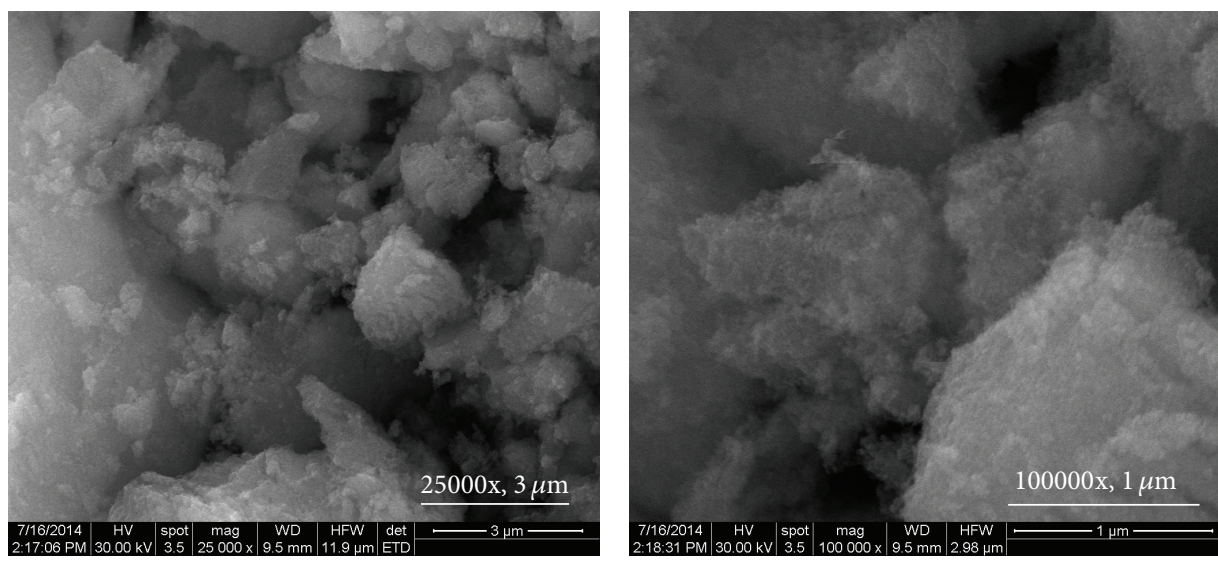

FIGURE 5: SEM image of HA-Ag nanopowder.
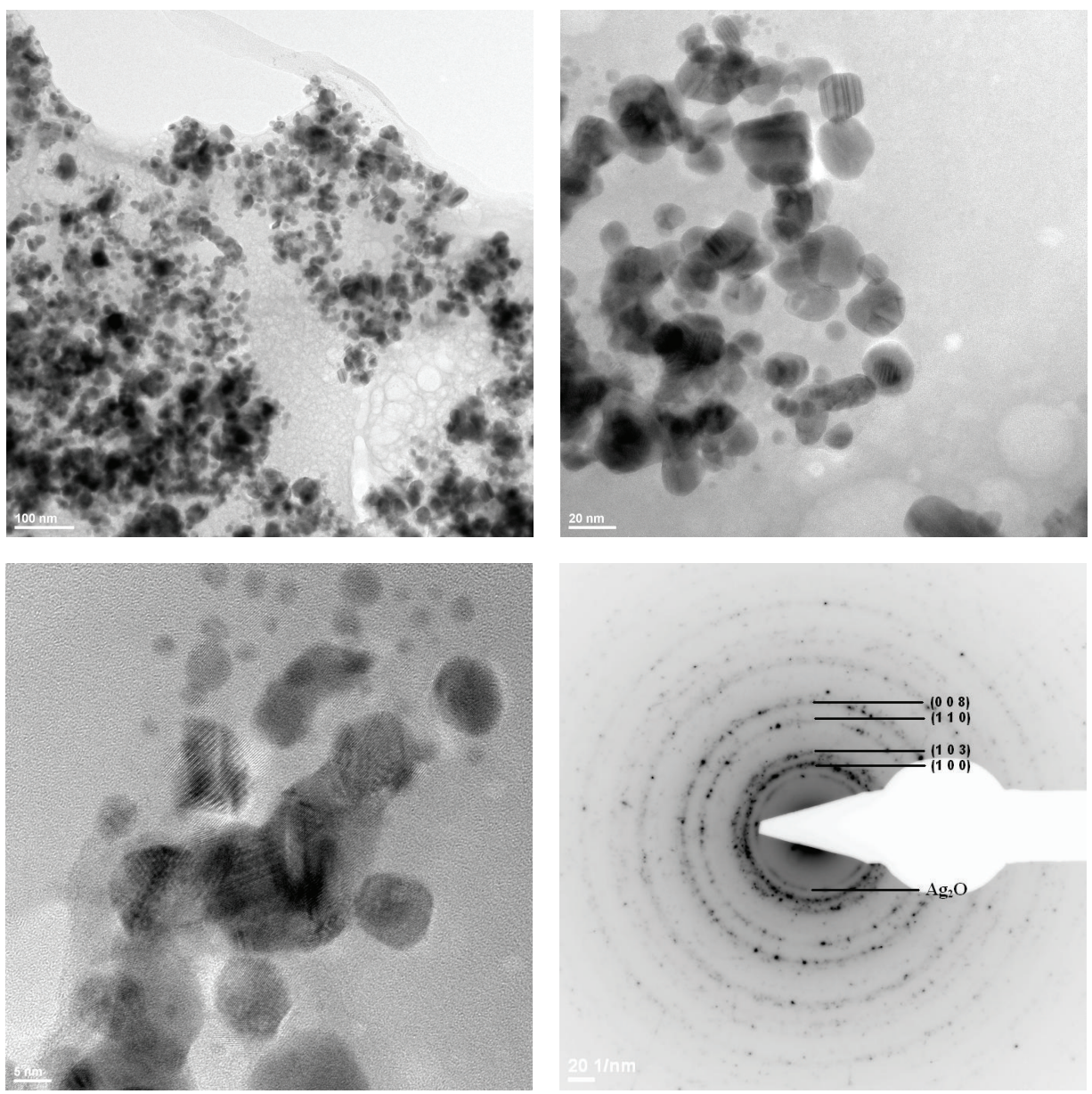

FIGURE 6: TEM images of plasma sputtered silver nanoparticles.

in the bulk nanopowder, it is possible to identify silver-rich areas (containing silver agglomerates) but also silver-free areas (pure HA). Based on TEM image, silver as well as HA can be considered monodisperse, silver having spherical form and a maximum diameter of less than $20 \mathrm{~nm}$.
3.5. Antimicrobial Studies. As found in the literature data, the antimicrobial activity is dependent on concentration, silver size, and shape [40]. Because only for the HA-Ag sample different compositions were obtained, the antimicrobial studies will be presented only for HA/Ag samples obtained by 


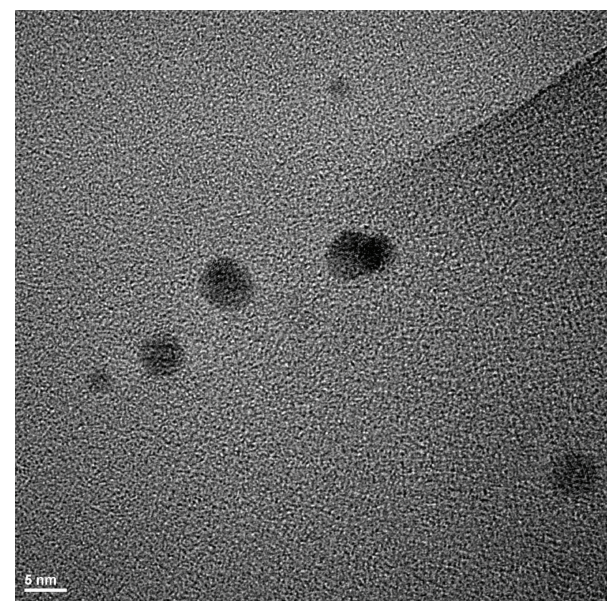

FIGURE 7: TEM image of the antiseptic COLL/Ag matrix.

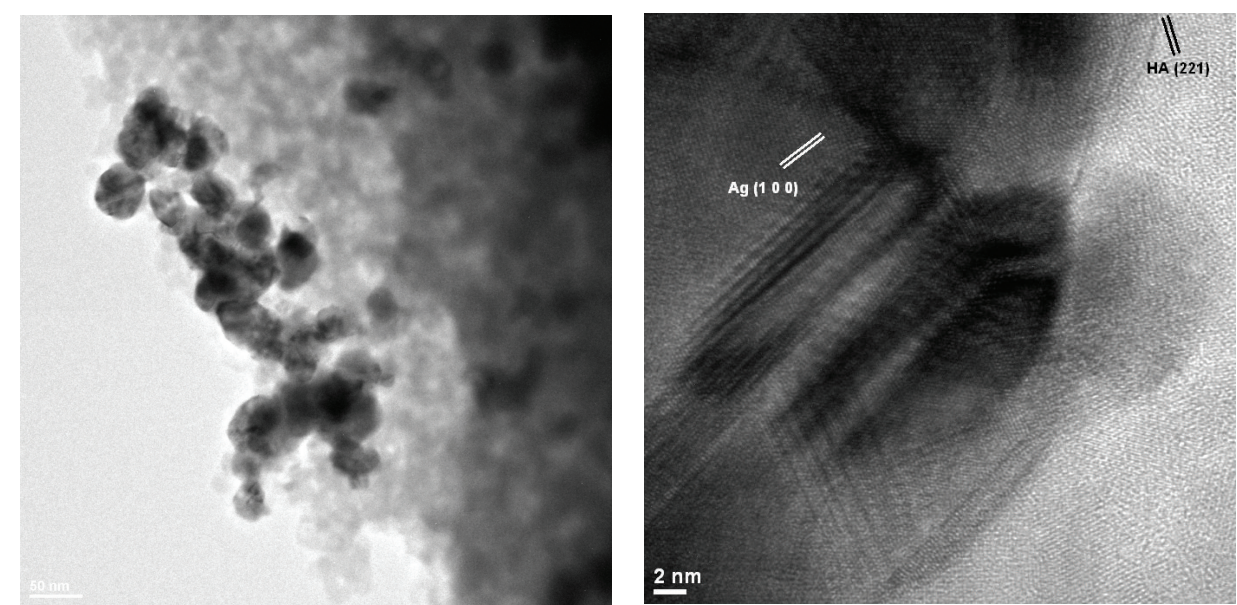

FIGURE 8: TEM images of HA-Ag powder.

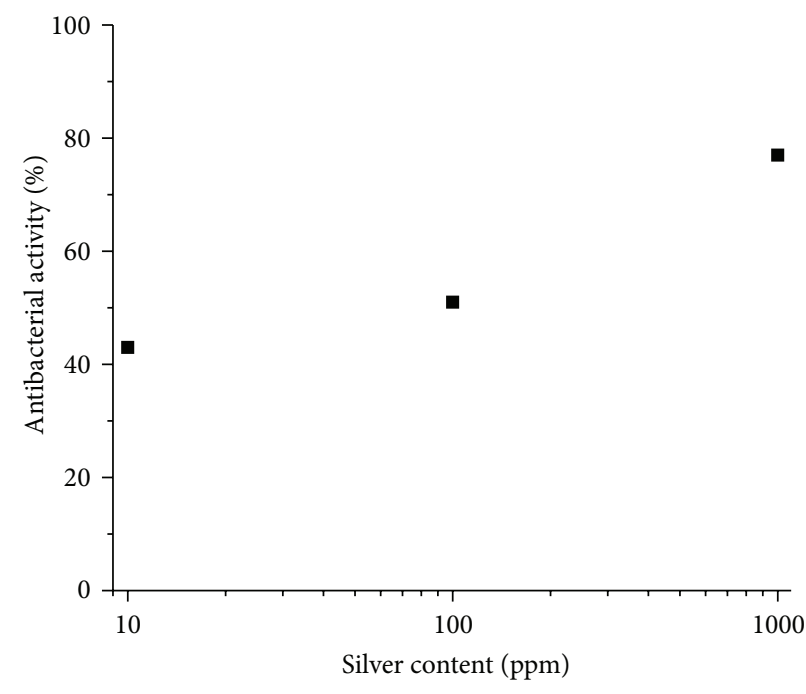

FIGURE 9: Antibacterial activity of the HA-Ag samples. 
TAble 1: Potential applications of the synthesized samples.

\begin{tabular}{lll}
\hline Materials & Synthesis method & Potential applications \\
\hline Colloidal silver & Chemical reduction & $\begin{array}{l}\text { Treatment of different infections (equivalent of antibiotics) or even cancer and so forth } \\
\text { COLL/Ag }\end{array}$ \\
& PS symmetric & $\begin{array}{l}\text { Skin cancer or burns (not recommended in the case of infections because glucose and its } \\
\text { derivatives could serve as a growth medium) } \\
\text { Skin cancer, infections associated with burns (can be used also for the people with } \\
\text { diabetes) } \\
\text { Skin cancer/infections (silver-rich face is in contact with the skin); } \\
\text { burns (silver-rich face is not in contact with the skin; Ag nanoparticles are only for their } \\
\text { antiseptic activity) }\end{array}$ \\
\hline $\begin{array}{l}\text { HA/Ag or } \\
\text { COLL/HA-Ag }\end{array}$ & PS symmetric & $\begin{array}{l}\text { Treatment of bone defects and even for bone cancer (Ag nanoparticles have antitumoral } \\
\text { activity and antiseptic activity, respectively) }\end{array}$ \\
& PS asymmetric & $\begin{array}{l}\text { Treatment of bone defects and bone cancer (silver-rich face has to be in contact with } \\
\text { cancerous tissue due to its antitumoral and antiseptic activity) }\end{array}$ \\
\hline
\end{tabular}

plasma sputtering and containing 10, 100, and 1000 ppm silver nanoparticles. The bacteriological experiments performed in vitro demonstrated the effectiveness of these samples in inhibiting the growth of Escherichia coli (Figure 9), even at low silver content.

It can be concluded that even at low content of silver nanoparticles $(10 \mathrm{ppm})$, the HA-Ag sample inhibits the growth of E. coli (43\%) while increasing content of silver induces a higher level of antimicrobial activity (51\% for $100 \mathrm{ppm}$ and $77 \%$ for $1000 \mathrm{ppm}$ of nanoAg, resp.).

Based on the presented results these materials are intended to be further tested for the following applications, as presented in Table 1 .

\section{Conclusions}

Three types of antiseptic, multifunctional materials were obtained, each having different potential medical applications. COLL/nanoAg is potential material for skin repair and can be used especially for the injuries caused by burns or cancer. HA/nanoAg and COLL/HA-nanoAg are potential bone grafts antiseptic materials but can be also used in different kinds of bone cancer, where surgical resection is necessary. Besides the material, in the cases of infections or tumours the silver-rich face of the materials has to be in contact with these tissues. When only antiseptic activity is required both symmetric (homogenous) and asymmetric materials can be used. In the cases of skin injuries it is recommended to use asymmetric COLL/Ag scaffolds and the silver-rich face does not have to be in contact with the skin, having only protective role for potential infections.

\section{Conflict of Interests}

The authors declare no conflict of interests.

\section{Acknowledgments}

This paper was supported by the PN-II-PT-PCCA-2011-3.20284: "Novel Nanostructured Prosthetic Tubular Devices with Antibacterial and Antibiofilm Properties Induced by
Physicochemical and Morphological Changes," funded by the National University Research Council in Romania.

\section{References}

[1] F. G. Rutberg, M. V. Dubina, V. A. Kolikov et al., "Effect of silver oxide nanoparticles on tumor growth in vivo," Doklady Biochemistry and Biophysics, vol. 421, no. 1, pp. 191-193, 2008.

[2] S.-L. Peng, D.-X. Chen, G. Su, Z. Wang, Y. H. Xiao, and Z. L. Liu, "Application of nanometer silver antiseptic dressing for wound surface in children after urinary surgery," Journal of Clinical Rehabilitative Tissue Engineering Research, vol. 11, no. 40, pp. 8181-8183, 2007.

[3] M. I. Sriram, S. B. M. Kanth, K. Kalishwaralal, and S. Gurunathan, "Antitumor activity of silver nanoparticles in Dalton's lymphoma ascites tumor model," International Journal of Nanomedicine, vol. 5, no. 1, pp. 753-762, 2010.

[4] M. Rahban, A. Divsalar, A. A. Saboury, and A. Golestani, "Nanotoxicity and spectroscopy studies of silver nanoparticle: calf thymus DNA and K562 as targets," Journal of Physical Chemistry C, vol. 114, no. 13, pp. 5798-5803, 2010.

[5] R. Xu, J. Ma, X. Sun et al., "Ag nanoparticles sensitize IR-induced killing of cancer cells," Cell Research, vol. 19, no. 8, pp. 1031-1034, 2009.

[6] Scopus Database, http://www.scopus.com.

[7] W. Zhang, X. Qiao, and J. Chen, "Synthesis of nanosilver colloidal particles in water/oil microemulsion," Colloids and Surfaces A: Physicochemical and Engineering Aspects, vol. 299, no. 1-3, pp. 22-28, 2007.

[8] A. R. Shahverdi, A. Fakhimi, H. R. Shahverdi, and S. Minaian, "Synthesis and effect of silver nanoparticles on the antibacterial activity of different antibiotics against Staphylococcus aureus and Escherichia coli," Nanomedicine: Nanotechnology, Biology, and Medicine, vol. 3, no. 2, pp. 168-171, 2007.

[9] W. Zhang, X. Qiao, J. Chen, and H. Wang, "Preparation of silver nanoparticles in water-in-oil aot reverse micelles," Journal of Colloid and Interface Science, vol. 302, no. 1, pp. 370-373, 2006.

[10] V.-S. Manoiu and A. Aloman, "Obtaining silver nanoparticles by sonochemical methods," UPB Scientific Bulletin, Series B: Chemistry and Materials Science, vol. 72, no. 2, pp. 179-186, 2010.

[11] H. V. Tran, L. D. Tran, C. T. Ba et al., "Synthesis, characterization, antibacterial and antiproliferative activities of monodisperse chitosan- based silver nanoparticles," Colloids 
and Surfaces A: Physicochemical and Engineering Aspects, vol. 360, no. 1-3, pp. 32-40, 2010.

[12] L.-H. Li, J.-C. Deng, H.-R. Deng, Z.-L. Liu, and X.-L. Li, "Preparation, characterization and antimicrobial activities of chitosan/ $\mathrm{Ag} / \mathrm{ZnO}$ blend films," Chemical Engineering Journal, vol. 160, no. 1, pp. 378-382, 2010.

[13] C. Zhang, Q. Yang, N. Zhan et al., "Silver nanoparticles grown on the surface of PAN nanofiber: preparation, characterization and catalytic performance," Colloids and Surfaces A: Physicochemical and Engineering Aspects, vol. 362, no. 1-3, pp. 58-64, 2010.

[14] F. Zeng, C. Hou, S. Wu, X. Liu, Z. Tong, and S. Yu, "Silver nanoparticles directly formed on natural macroporous matrix and their anti-microbial activities," Nanotechnology, vol. 18, no. 5, Article ID 055605, 2007.

[15] O. V. Melnikov, O. Y. Gorbenko, M. N. Mărkelova et al., "Agdoped manganite nanoparticles: new materials for temperaturecontrolled medical hyperthermia," Journal of Biomedical Materials Research, Part A, vol. 91, no. 4, pp. 1048-1055, 2009.

[16] C.-S. Wu, C.-Y. Lee, J.-K. Chen et al., "Microwave-assisted electroless deposition of silver nanoparticles onto multiwalled carbon nanotubes," International Journal of Electrochemical Science, vol. 7, no. 5, pp. 4133-4142, 2012.

[17] C. S. Ciobanu, S. L. Iconaru, P. Le Coustumer, L. V. Constantin, and D. Predoi, "Antibacterial activity of silver-doped hydroxyapatite nanoparticles against gram-positive and gram-negative bacteria," Nanoscale Research Letters, vol. 7, article 324, 2012.

[18] C. S. Ciobanu, S. L. Iconaru, P. le Coustumer, and D. Predoi, "Vibrational investigations of silver-doped hydroxyapatite with antibacterial properties," Journal of Spectroscopy, vol. 2013, Article ID 471061, 5 pages, 2013.

[19] M. A. Hettiarachchi and P. A. S. R. Wickramarachchi, "Synthesis of chitosan stabilized silver nanoparticles using gamma ray irradiation and characterization," Journal of Science-University of Kelaniya, vol. 6, pp. 65-75, 2011.

[20] M. G. Albu, Collagen Gels and Matrices for Biomedical Applications, edited by E. Alexei, Lambert Academic Publishing, Saarbrücken, Germany, 2011.

[21] M. G. Albu, I. Titorencu, and M. V. Ghica, "Collagen-based drug delivery systems for tissue engineering," in Biomaterials Applications for Nanomedicine, P. Rosario, Ed., chapter 17, InTech, Rijeka, Croatia, 2011.

[22] M. G. Albu, V. Trandafir, D. M. Suflet, G. C. Chitanu, P. Budrugeac, and I. Titorencu, "Biocomposites based on collagen and phosphorylated dextran for bone regeneration," Journal of Materials Research, vol. 27, no. 7, pp. 1086-1096, 2012.

[23] A. Ficai, E. Andronescu, V. Trandafir, C. Ghitulica, and G. Voicu, "Collagen/hydroxyapatite composite obtained by electric field orientation," Materials Letters, vol. 64, no. 4, pp. 541544,2010

[24] A. Ficai, E. Andronescu, G. Voicu, and D. Ficai, "Advances in collagen/hydroxyapatite composite materials," in Advances in Composite Materials for Medicine and Nanotechnology, B. Attaf, Ed., InTech, 2011.

[25] A. Ficai, E. Andronescu, G. Voicu et al., "Self-assembled collagen/hydroxyapatite composite materials," Chemical Engineering Journal, vol. 160, no. 2, pp. 794-800, 2010.

[26] A. Ficai, E. Andronescu, G. Voicu, D. Manzu, and M. Ficai, "Layer by layer deposition of hydroxyapatite onto the collagen matrix," Materials Science \& Engineering C-Materials for Biological Applications, vol. 29, no. 7, pp. 2217-2220, 2009.
[27] A. Ilie, E. Andronescu, D. Ficai et al., "New approaches in layer by layer synthesis of collagen/hydroxyapatite composite materials," Central European Journal of Chemistry, vol. 9, no. 2, pp. 283-289, 2011.

[28] D. I. Ilan and A. L. Ladd, "Bone graft substitutes," Operative Techniques in Plastic and Reconstructive Surgery, vol. 9, no. 4, pp. 151-160, 2002.

[29] R. Murugan and S. Ramakrishna, "Development of nanocomposites for bone grafting," Composites Science and Technology, vol. 65, no. 15-16, pp. 2385-2406, 2005.

[30] S. Bandyopadyay-Ghosh, "Bone as a collagen-hydroxyapatite composite and its repair," Trends in Biomaterials and Artificial Organs, vol. 22, no. 2, pp. 112-120, 2008.

[31] S. N. Parikh, "Bone graft substitutes: past, present, future," Journal of Postgraduate Medicine, vol. 48, no. 2, pp. 142-148, 2002.

[32] B. H. Ziran, W. R. Smith, and S. J. Morgan, "Use of calciumbased demineralized bone matrix/allograft for nonunions and posttraumatic reconstruction of the appendicular skeleton: preliminary results and complications," The Journal of Trauma, vol. 63, no. 6, pp. 1324-1328, 2007.

[33] D.-J. Yang, C.-D. Xiong, T. Govender, and Y.-Z. Wang, "Preparation and drug-delivery potential of metronidazole-loaded PELA tri-block co-polymeric electrospun membranes," Journal of Biomaterials Science, Polymer Edition, vol. 20, no. 9, pp. 1321$1334,2009$.

[34] D. Dorjnamjin, M. Ariunaa, and Y. K. Shim, "Synthesis of silver nanoparticles using hydroxyl functionalized ionic liquids and their antimicrobial activity," International Journal of Molecular Sciences, vol. 9, no. 5, pp. 807-820, 2008.

[35] V. K. Sharma, R. A. Yngard, and Y. Lin, "Silver nanoparticles: green synthesis and their antimicrobial activities," Advances in Colloid and Interface Science, vol. 145, no. 1-2, pp. 83-96, 2009.

[36] E. Andronescu, M. Ficai, G. Voicu, D. Ficai, M. Maganu, and A. Ficai, "Synthesis and characterization of collagen/ hydroxyapatite: magnetite composite material for bone cancer treatment," Journal of Materials Science: Materials in Medicine, vol. 21, no. 7, pp. 2237-2242, 2010.

[37] A. Ficai, E. Andronescu, G. Voicu, C. Ghitulica, and D. Ficai, "The influence of collagen support and ionic species on the morphology of collagen/hydroxyapatite composite materials," Materials Characterization, vol. 61, no. 4, pp. 402-407, 2010.

[38] M. A. Ansari, H. M. Khan, A. A. Khan et al., "Evaluation of antibacterial activity of silver nanoparticles against MSSA and MRSA on isolates from skin infections," Biology and Medicine, vol. 3, no. 2, pp. 141-146, 2011.

[39] S. Jaiswal, B. Duffy, A. K. Jaiswal, N. Stobie, and P. McHale, "Enhancement of the antibacterial properties of silver nanoparticles using $\beta$-cyclodextrin as a capping agent," International Journal of Antimicrobial Agents, vol. 36, no. 3, pp. 280-283, 2010.

[40] I.-A. Nedelcu, A. Ficai, M. Sonmez, D. Ficai, O. Oprea, and E. Andronescu, "Silver based materials for biomedical applications," Current Organic Chemistry, vol. 18, no. 2, pp. 173-184, 2014. 

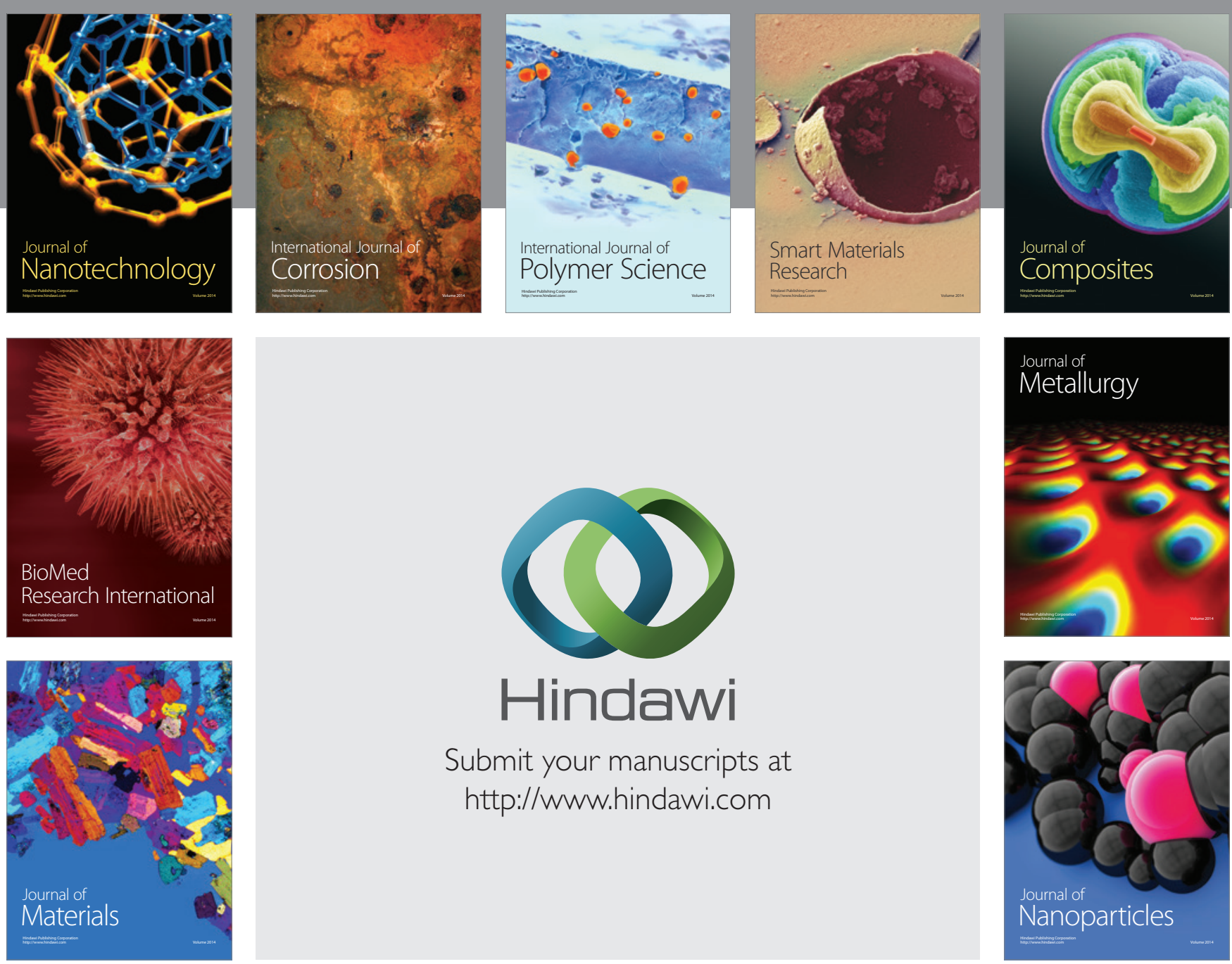

Submit your manuscripts at http://www.hindawi.com
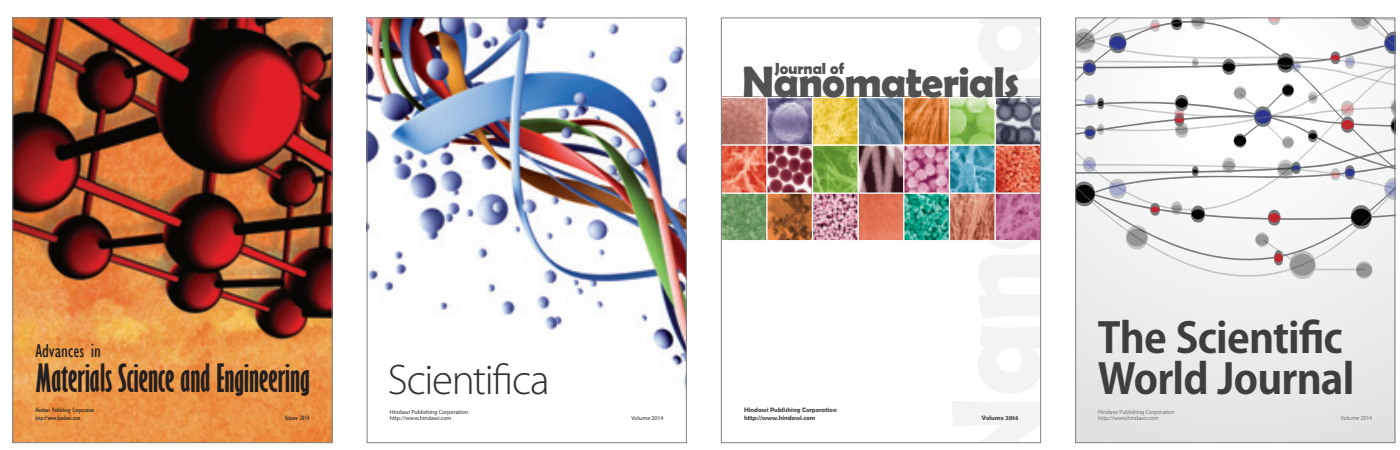

\section{The Scientific World Journal}
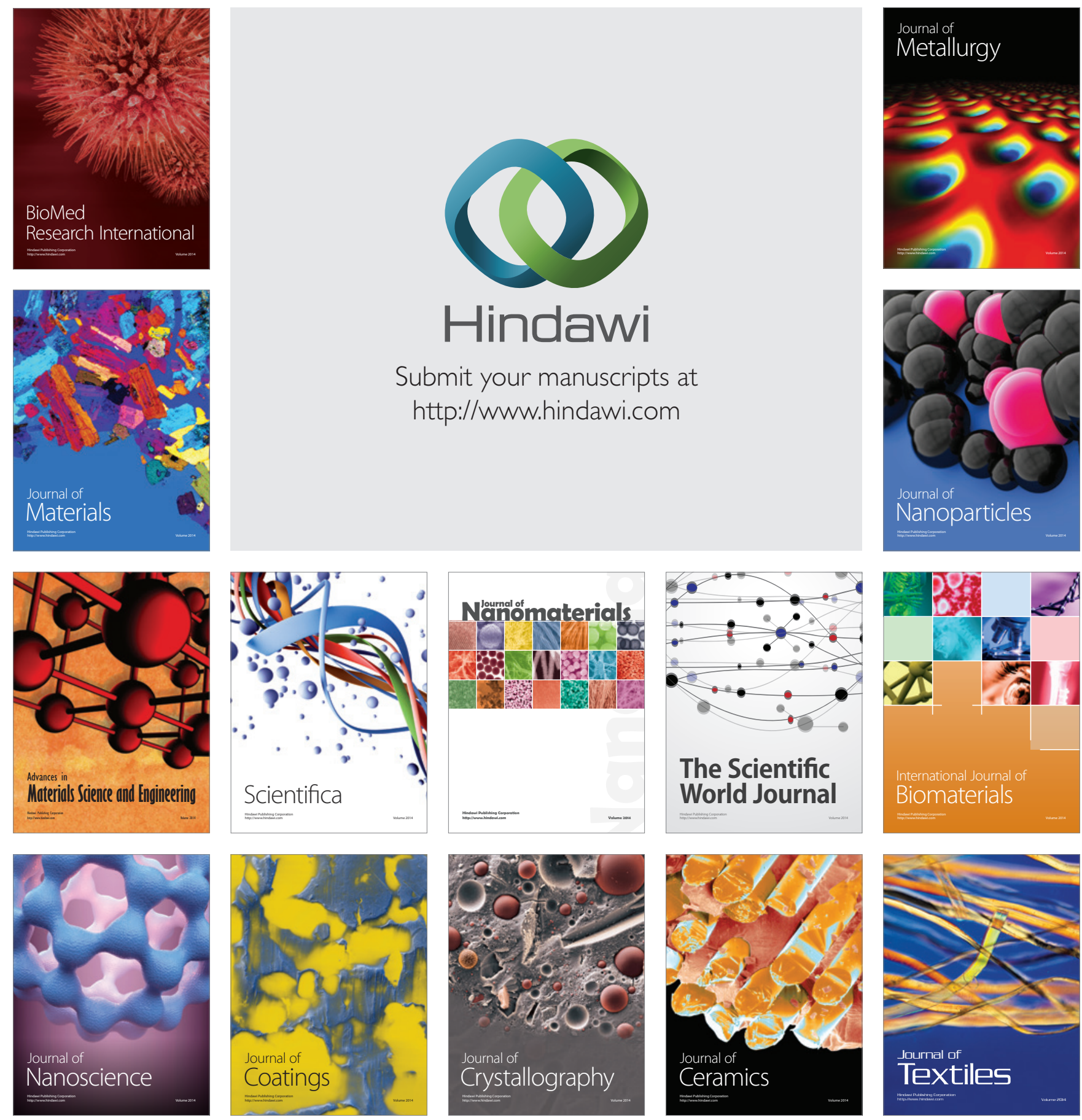